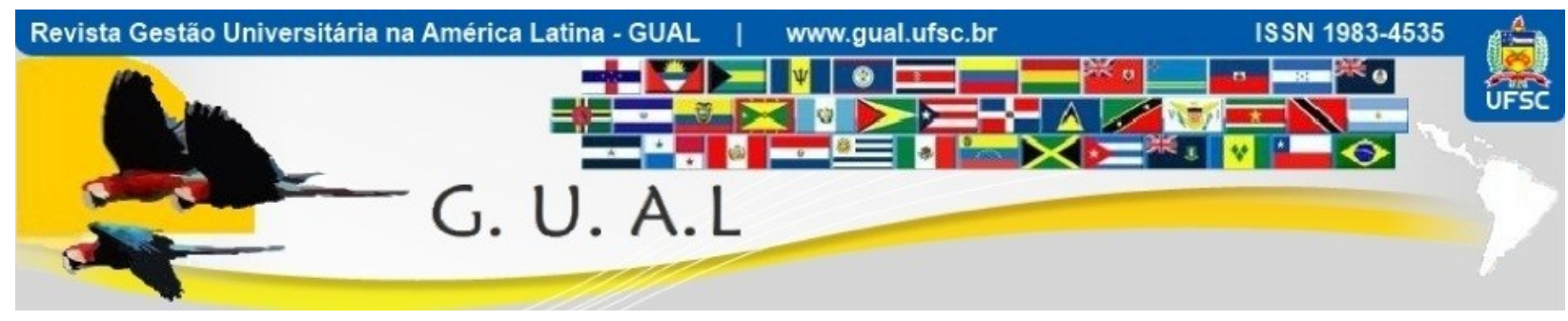

DOI: http://dx.doi.org/10.5007/1983-4535.2012v5n4p100

\title{
OS CURSOS SUPERIORES DE TECNOLOGIA E O MUNDO DO TRABALHO
}

\author{
THE COURSES IN TECHNOLOGY AND THE WORLD OF WORK
}

Edson Andrade dos Reis, Mestre

Faculdade Anhanguera de Joinville edson.reis@aesapar.com

Everson Andrade dos Reis, Mestre Universidade Estadual Paulista - UNESP eversonareis@yahoo.com.br

Recebido em 16/novembro/2012

Aprovado em 07/dezembro/2012

Sistema de Avaliação: Double Blind Review

Esta obra está sob uma Licença Creative Commons Atribuição-Uso. 


\begin{abstract}
RESUMO
Com a crescente inovação tecnológica no âmbito das organizações, tornou-se clara a necessidade de uma estreita relação entre a instituição produtora do saber, conhecimento técnico e científico e as empresas. o objetivo principal deste trabalho é abordar as interações dos cursos superiores de tecnologias e as empresas, de forma a auxiliar as análises de um curso de tecnologia e sua inserção no junto do trabalho como forma a contribuir ao desenvolvimento da sociedade e o aumento do percentual da população com nível superior no país. no presente estudo. A coleta de dados foi realizada por meio do método de entrevistas com gestores das empresas das regiões de Brasília, Joinville e São Paulo utilizando-se um questionário semi-estruturado. A pesquisa foi aplicada entre os dias 20 de julho a 10 de setembro de 2012, onde foram coletados 51 questionários, sendo 24 questionários de gestores da cidade de Brasília, 18 questionários de gestores da cidade de Joinville e 9 questionários da cidade de São Paulo. Os cursos superiores de tecnologia não estão desenvolvendo as potencialidades do ensino superior profissionalizante na sua plenitude principalmente pela falta de interação das empresas no modelamento das matrizes curriculares.
\end{abstract}

Palavras-chave: Ensino superior. Tecnólogo. Matrizes curriculares.

\begin{abstract}
With increasing technological innovation within organizations, it became clear the need for a close relationship between the institution of knowledge production, scientific and technical knowledge and business. The main objective of this work is to address the interactions of courses in technology and business, in order to assist the analysis of a course of technology and its integration into the work together as a way to contribute to the development of society and the increasing percentage of the population with higher education in the country. in this study. Data collection was performed by the method of interviews with corporate managers regions of Brasilia, Sao Paulo and Joinville using a semi-structured questionnaire. The survey was carried out between 20 July and 10 September 2012, where 51 questionnaires were collected, of which 24 questionnaires from managers of the city of Brasília, 18 questionnaires from managers of the city of Joinville and 9 questionnaires city of São Paulo. The courses in technology are not developing the potential of vocational higher education in its fullness mainly by the lack of interaction between enterprises in shaping the curriculum matrices.
\end{abstract}

Keywords: Higher education. Technologist. Curriculum matrix. 


\section{INTRODUÇÃO}

Com a conscientização da importância do aprendizado por parte da sociedade, e com um grande esforço direcionado para a melhoria da educação é possível vislumbrar que no futuro o Brasil deixe de ser apenas um país com grande economia, e se transforme em uma potência desenvolvida, com maiores oportunidades de negócios. Assim, a Universidade visa a atingir seu papel pela confirmação como centro produtor de conhecimento, além de contribuir para o desenvolvimento das empresas locais cujos relacionamentos estejam estabelecidos.

Com a crescente inovação tecnológica no âmbito das organizações, tornou-se clara a necessidade de uma estreita relação entre a instituição produtora do saber, conhecimento técnico e científico e as empresas, para o seu bom funcionamento. Esse intercâmbio visa reconhecer a importância dos mecanismos de interação entre "Universidade e Empresa" para o desenvolvimento local e regional, como uma ferramenta preponderante, de forma a ser assimilado pela sociedade, tendo em vista o aumento da qualidade e da formação dos profissionais, para que estejam aptos a responder adequadamente aos desafios ocasionados pela sociedade globalizada centrada no conhecimento, habilidades e atitudes.

A necessidade atual do mercado de trabalho é possuir conhecimento prático para alavancar suas potencialidades e sua conseqüente excelência. Neste contexto é que surgem os cursos superiores tecnólogos, para aliar o conhecimento científico, amplamente divulgado nos cursos de bacharelado, com a aplicação prática visualizada no ensino técnico (nível médio).

Assim como outras empresas, as instituições de ensino superior estão em constantes e rápidas transformações. Saber lidar com essas transformações para garantir sua sobrevivência no mercado cada vez mais competitivo e exigente é um grande desafio.

Em virtude de seu caráter interdisciplinar, as instituições de ensino superior interagem com um maior número de segmentos da sociedade do que qualquer outra organização isoladamente, e sua gestão tem sido parte da agenda de discussão em instâncias políticas como acadêmicas.

A Instituição Ensino Superior (IES) está sujeita, por sua própria essência, aos desafios que lhe são impostos de gestão e, ao mesmo tempo, construção da qualidade dentro de cenários altamente dinâmicos.

No entorno da instituição do ensino superior há também uma expectativa da sociedade em relação à qualidade dos serviços prestados por esta, tomada da consciência de 
que melhorias contínuas são necessárias para alcançar e assegurar o alto desempenho científico, econômico e social de todos.

A IES deve ser estruturada para atender o mundo do trabalho, mundo científico e acadêmico, sendo a sua qualidade expressão maior de reverência da sociedade. Diante deste contexto de transformações desafiadoras, algumas instituições de ensino superior têm ofertado cursos de tecnologia de maneira a buscar estreitar a lacuna entre o mundo do trabalho e as suas relações com a academia.

Doravante estes cursos podem corresponder ao acesso de uma maior parte da população quem busca a formação superior e a conseqüente formação profissional em nível superior, porém as diretrizes para estes cursos não correspondem com a visualização da formação de mão-de-obra especializada. Cursos com caráter finito, sem a interface com as realidades de gestão e de sustentabilidade colaboram para que esta modalidade não decole como opção de remediar esta condição.

É necessário, portanto, introduzir novas formas de gestão acadêmicas que conduzam a maior motivação, produtividade e obtenção de resultados, que possam traduzir-se em benefícios concretos para a sociedade.

Para tanto, o objetivo principal deste trabalho é abordar as interações dos cursos superiores de tecnologias e as empresas, de forma a auxiliar as análises de um curso de tecnologia e sua inserção no junto do trabalho como forma a contribuir ao desenvolvimento da sociedade e o aumento do percentual da população com nível superior no país.

Desta forma os problemas de pesquisa que a pesquisa pretende abordar são de que forma os cursos superiores de tecnologia estão desenvolvendo as potencialidades do ensino superior profissionalizante? Como o mundo do trabalho é articulado com os cursos superiores de tecnologia?

\section{REFERÊNCIAL TEÓRICO}

Neste capítulo apresenta-se o referencial teórico sobre o tema afim de embasar a pesquisa em conceitos da integração conhecimento científico $x$ aplicação prática, particularidades do curso de tecnólogo e as diferenças entre bacharelado e tecnólogo.

\subsection{INTEGRAÇÃO CONHECIMENTO CIENTÍFICO X APLICAÇÃO PRÁTICA}

O mercado de trabalho almeja um profissional capaz de fundamentar o espírito crítico, fundamentado pelo conhecimento científico e realizador de ações que oportunizem soluções 
de problemas via realização da integração entre o conhecimento cientifico a sua aplicação prática.

Desta forma as IES detém um importante papel neste contexto com o propósito de interagir o capital intelectual com as demandas que o mercado solicita, onde Universidades, que é um termo genérico utilizado para identificar uma instituição de ensino superior, um centro universitário ou uma faculdade isolada, pública ou privada (PLONSKI, 1998), possa ser assim conceituada:

Centro irradiador de ciências, a universidade deve estar aberta aos adultos, aos profissionais que já estão colocados no mercado de trabalho e que precisam pensar, reciclar e criar projetos à velocidade das mutações tecnológicas da sociedade do conhecimento. [...]. O propósito da aliança do conhecimento com instituições de ensino é a ampliação do capital intelectual visando atender à demanda do mercado (FIORI, 2001, p. 9) .

A relação entre universidade e empresa, que visa a aplicação pratica da cientificidade, é um processo complexo que envolve diferentes lógicas, desenvolvendo-se em referenciais distintos. A universidade e a empresa, segundo Brisolla (1998, p. 35), podem representar:

[...] dois mundos, duas culturas. Os espaços acadêmicos, com sua linguagem esotérica, seus rituais, seus mecanismos de legitimação e reconhecimento, feitos pela comunidade científica. O âmbito empresarial, com o pragmatismo que lhe é característico, na limpidez dos objetivos, claramente estabelecidos, com uma lógica irrefutável, ditada pela luta pela sobrevivência.

Para Vieira e Kunz (2001, p. 65), "com a importância crescente das inovações tecnológicas no âmbito das empresas, tornou-se clara a necessidade de uma estreita relação entre as instituições produtoras de saber, de conhecimento técnico e científico, e as empresas."

\subsection{PARTICULARIDADES DO CURSO DE TECNÓLOGO}

Os Cursos de Tecnologia têm duração de 4 a 6 semestres letivos e estrutura formada por dois ciclos distintos e verticalizados. A conclusão do primeiro, denominado ciclo profissional geral, correspondendo a dois a três semestres e estágio supervisionado, permite a diplomação como Técnica, na modalidade de curso superior seqüencial. O acesso ao segundo ciclo, denominado ciclo modal, se dá mediante seleção específica e a sua conclusão habilita o estudante como graduado em Tecnologia ou Tecnólogo.

Souza (1999) afirma que é preciso:

um sistema em que convivam universidades, faculdades e instituições que se dediquem só ao ensino, como os centros universitários. O sistema tem de ser 
diversificado na estrutura das instituições e na oferta dos cursos. /.../ Tem-se que ter mais flexibilidade também na organização dos cursos. É o que a resolução do Conselho Nacional de Educação [Resolução CES 01/99] vai permitir: cursos mais curtos que dão alguma certificação e já servem para uma espécie de profissionalização. $\mathrm{O}$ aluno pode fazer um curso de dois anos e ganhar uma certificação. Então, sai, trabalha, depois volta, faz mais outro e pode até obter o diploma de graduação, se completar a carga horária que lhe daria direito a isso.

Conforme Prado (2006, p. 125), "Nesse contexto notadamente a educação tecnológica, premida pelas sucessivas alterações na economia e no mundo do trabalho, tem de mudar sua mentalidade e métodos.".

Nessa linha, o curso de tecnólogo se propõe a oferecer condições para o desenvolvimento tecnológico do setor industrial brasileiro. A tecnologia é disseminada através de serviços como assessoria técnica e tecnológica, ensaios laboratoriais, pesquisa aplicada, difusão de informação tecnológica e, especialmente, educação profissional, que possui o intuito de formar uma massa crítica capaz de pensar e repensar continuamente o processo produtivo. O incremento destas ações está associado à criação, a partir de 1994, dos Centros de Tecnologia voltados ao atendimento dos mais expressivos setores industriais do país.

Para Prado (2006, p. 148), o Decreto 2.208/97 dividiu a educação profissional em três níveis:

a) Nível Básico, modalidade de educação profissional não-formal, de duração variável, oferecida a estudantes e trabalhadores com qualquer grau de escolaridade, a fim de qualificá-los, requalificá-los e profissionalizá-los;

b) Nível Técnico, com organização curricular própria, a ser oferecido a alunos matriculados egresso do Ensino Médio, mas independente deste, podendo ser oferecido de forma concomitante ou seqüencial, sendo permitido o aproveitamento de até $25 \%$ do total da carga horária mínima do Nível Médio, das disciplinas profissionalizantes nele cursadas, em currículo de habilitação profissional, os currículos de Ensino Técnico serão estruturados em disciplinas que poderão ser agrupadas em módulos com caráter de terminalidade para efeitos de Qualificação Profissional;

c) Nível Tecnológico, a ser oferecido em nível superior na área tecnológica para alunos egressos do ensino médio e técnico, por meio de processo seletivo.

A proposta da educação profissional do curso de tecnólogo está embasada na viabilização de condições de disputa das melhores oportunidades de trabalho e renda, num processo contínuo e permanente. Para tanto, desenvolve-se uma educação profissional nos níveis básico, técnico, tecnológico e até de pós-graduação. 


\subsection{DIFERENÇAS ENTRE BACHARELADO E TECNÓLOGO}

É importante que se entenda as diferenças existentes entre universidades tradicionais (bacharelado) e Ensino superior profissional (tecnólogos), as quais ficam melhor evidenciadas em seus aspectos quando mostradas conforme figura 1. Assim, consegue-se visualizar melhor as diferenças que ocorrem na relação entre o sistema de educação profissional, a educação escolar e o mercado de trabalho.

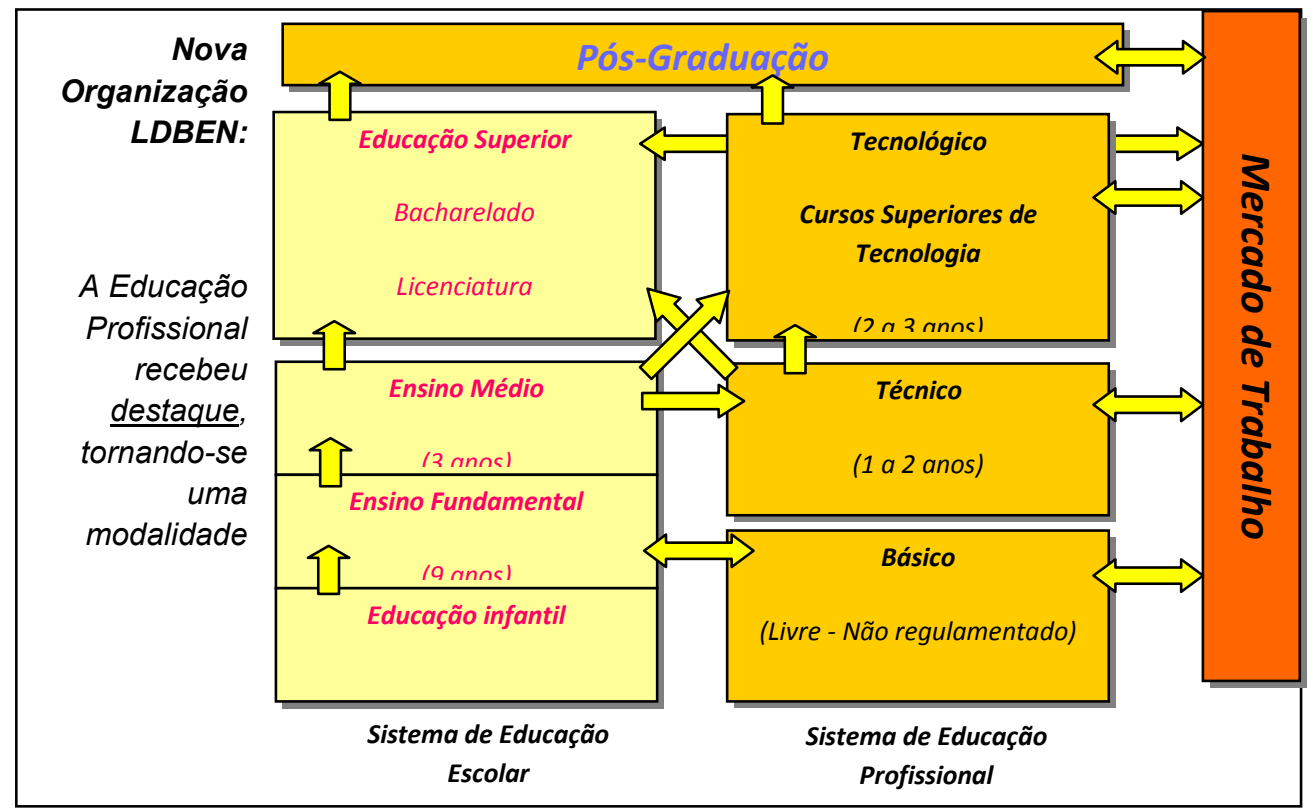

Figura 1 Relação entre o sistema de educação profissional, a educação escolar e o mercado de trabalho

Fonte: adaptado do INEP

Conforme Prado (2006, p. 166), "os bacharelados são os tradicionais cursos que preparam para uma carreira acadêmica ou profissional, tendo, em média, quatro anos de duração. O grau de bacharel habilita seu portador a exercer profissão de nível superior."

Para Schneider (2005), Os bacharelados reforçam o conhecimento teórico e acadêmico, propondo uma formação, ainda, muito tradicional. Já a formação de tecnólogos busca trabalhar a prática como ferramenta para a construção do conhecimento. Deve-se reforçar que a formação não está somente preocupada com a prática, mas principalmente em como mobilizar os conhecimentos, habilidades e atitudes na resolução de problemas. Uma formação mais dinâmica e prática, porém, não deve ser confundida com menos especialização, pelo contrário, propõe profundidade, conhecimento focado e contextualizado, autonomia e educação continuada. 
"O curso tecnológico ou de graduação tecnológica, forma tecnólogos para o mundo do trabalho, sendo mais focados, específicos e com duração suficiente e adequada para preparar profissionais para o mercado de trabalho local/regional." (PRADO, 2006, p. 166).

Diante disso, descobre-se que a educação de cunho tecnológico, está voltada para a capacitação dinâmica e criativa, de acordo com os objetivos organizacionais locais e o cotidiano do seu trabalho, aprimorando continuamente sua capacidade produtiva, enquanto as universidades tradicionais, por meio do ensino de graduação bacharelado e licenciatura, além dos cursos seqüenciais, reúnem as condições de aprendizagem para gerar e transmitir o conhecimento científico para as empresas. Esta possui um maior foco direcionado para a pesquisa, aquela um maior foco direcionado para o mercado profissional.

\section{METODOLOGIA}

Ruiz (1996) afirma que a pesquisa científica é a realização de um estudo planejado, sendo o método de abordagem do problema o que caracteriza o aspecto científico da investigação.

Marconi e Lakatos (2002) mencionam que os métodos e as técnicas a serem empregados na pesquisa científica podem ser selecionados desde a proposição do problema, da formulação das hipóteses e da delimitação do universo ou da amostra.

$\mathrm{Na}$ seqüência, explicita-se o delineamento da pesquisa, define-se a população e amostra do estudo e expõem-se a coleta de dados. Por último, abordam-se a análise de dados e limitações da pesquisa.

\subsection{DELINEAMENTO DA PESQUISA}

No presente estudo quanto aos objetivos, o método aplicado é descritivo. Gil (1999, p. 70) comenta que "a pesquisa descritiva tem como principal objetivo descrever características de determinada população ou fenômeno ou estabelecimento de relações entre as variáveis". A pesquisa é considerada qualitativa por interpretar as condições exitosas de IES que ofertam cursos de tecnologia e a ótica desses cursos para as empresas que absorvem esses profissinais, articulando positivamente com o mercado profissional.

\subsection{POPULAÇÃO E AMOSTRA}

Segundo Gil (1999), população é o conjunto de elementos que possuem determinadas características. 
No presente estudo, a população da pesquisa é constituída por gestores de empresas de três regiões do Brasil: Distrito Federal, Santa Catarina e São Paulo representadas pelas cidades de Brasília, Joinville e São Paulo, respectivamente. Ainda a população foi constituída principalmente por empresas do setor privado e, em Brasília, por representatividade do setor público federal.

Para Marconi e Lakatos (2002), na amostra intencional, o pesquisador está interessado na ação de determinados elementos da população, mas não representativos dela. Caracteriza-se, ainda, como amostra intencional de acordo com Martins (1994, p. 40), “é escolhida intencionalmente um grupo de elementos que irão compor a amostra".

\subsection{PROCEDIMENTOS DE COLETA DE DADOS}

Explicam Marconi e Lakatos (2002, p. 32) que coleta de dados é "a etapa da pesquisa em que se inicia a aplicação dos instrumentos elaborados selecionadas, a fim de se efetuar a coleta dos dados previstos".

A coleta de dados foi realizada por meio do método de entrevistas com gestores das empresas das regiões de Brasilia, Joinville e São Paulo utilizando-se um questionário semiestruturado.

A pesquisa foi aplicada entre os dias 20 de julho a 10 de setembro de 2012, onde foram coletados 51 questionários, sendo 24 questionários de gestores da cidade de Brasília, 18 questionários de gestores da cidade de Joinville e 9 questionários da cidade de São Paulo.

“A entrevista é uma técnica importante para o desenvolvimento de uma estreita relação entre as pessoas, resultando na interação entre elas, considerado como um elemento fundamental na pesquisa em Ciências Sociais”(RICHARDSON, 1999, p. 26).

\subsection{ANÁLISE E INTERPRETAÇÃO DOS DADOS}

Para Colauto e Beuren (2006), a análise deve ser feita para atender aos objetivos da pesquisa e para comparar e confrontar dados e provas, no intuito de confirmar ou rejeitar hipóteses ou pressupostos da pesquisa.

Dessa forma, a interpretação dos dados realizará a comparação das visões dos gestores das três regiões analisadas, verificando a proximidade das grades curriculuares dos cursos de tecnologia com a demanda do mercado de trabalho oferecida nos locais determinado da população da referente pesquisa. 


\subsection{LIMITAÇÕES DA PESQUISA}

A presente pesquisa a análise de três cidades brasileira: Brasília-DF, Joinville-SC e São Paulo-SP. Dessa forma, as praticas desenvolvidas em Universidades e outras IES privadas de outras regiões não são interpretadas, gerando assim uma limitação de que o modelo está concebido em sua representatividade para IES das regiões acima mencionadas.

\section{RESULTADOS DA PESQUISA}

Após a análise e compilação dos questionários aplicados durante a coleta de dados, com vistas a tentar encontrar a percepção dos gestores de empresas, no escopo determinado na população e amostra da pesquisa, verificou-se as interações dos cursos superiores de tecnologias e com a realidade das necessidades das empresas, de forma a auxiliar as análises de um curso de tecnologia e sua inserção no junto ao mercado de trabalho.

$\mathrm{Na}$ análise da importância dos cursos superiores de tecnologia para o mercado de trabalho, a grande maioria dos entrevistados mencionou como "boa" $(64,70 \%)$ e "excelente" (11.75\%). Entretanto, destaca-se a visão dos gestores de Brasília apresentando "pouca" (11.75\%) essa importância. O gráfico 1 apresenta os dados referente a essa análise.

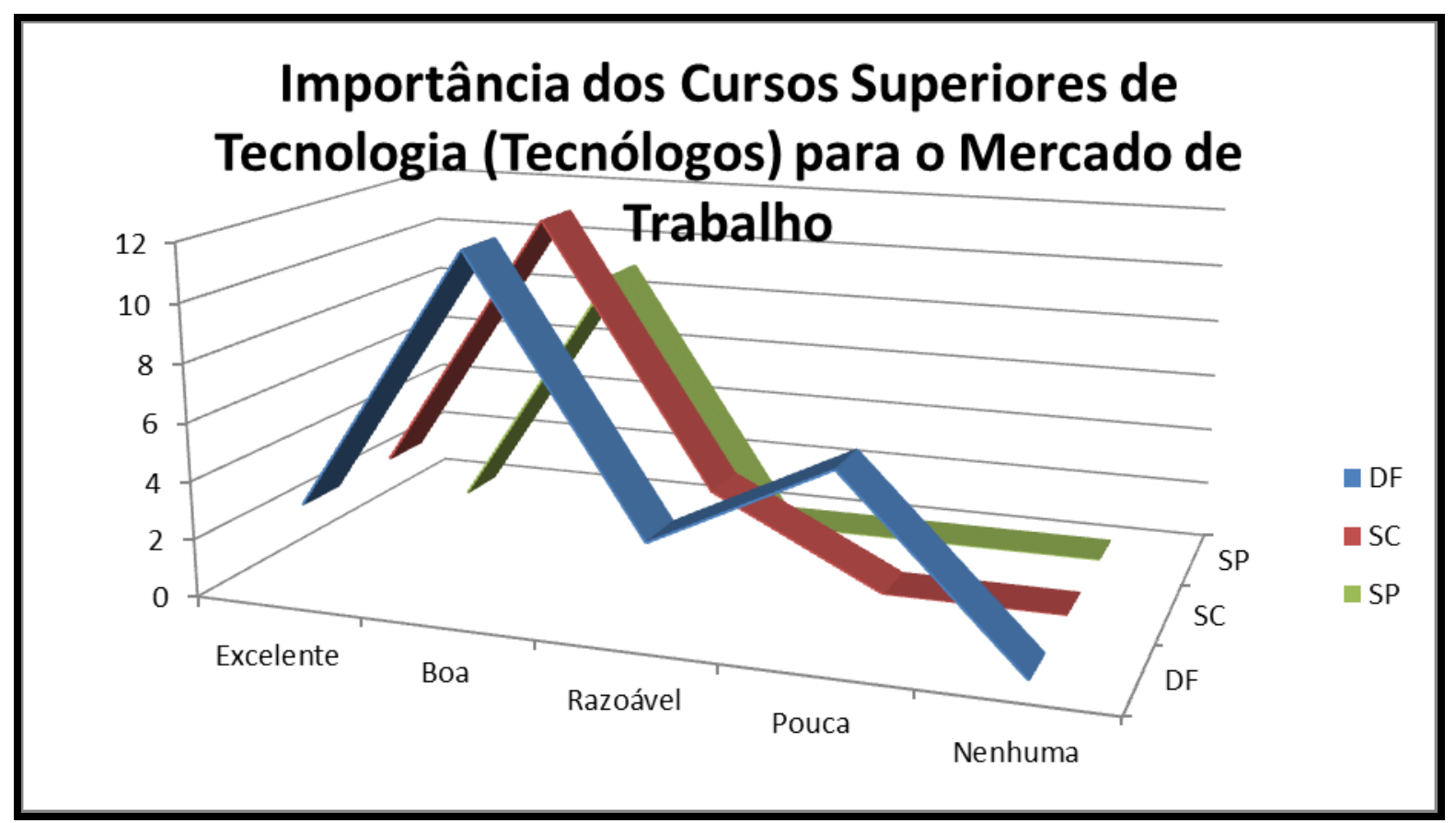

Gráfico 1 Importância dos Curso Superiores de Tecnologia.

Fonte: Os autores.

Na análise da visão dos gestores quanto à formação de funcioários com a graduação em tecnologia, a maioria dos entrevistados mencionou como "boa" $(41,17 \%)$ e ainda como 
“excelente" (23,52\%) e razoável $(23,52 \%)$ essa visão. Isso permite concluir que os gestores, independentemente da região abordada na pesquisa possuem uma visão positiva dos cursos tecnólogos. A representação do gráfico 2 demonstra essa análise.

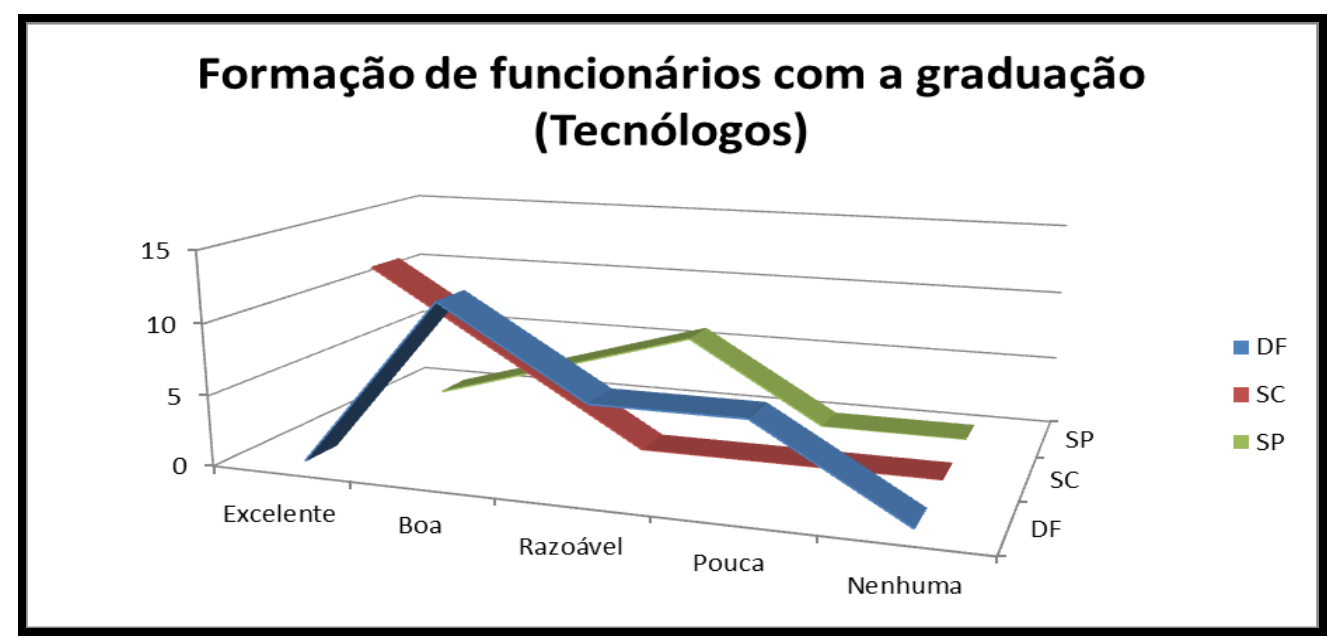

Gráfico 2 Formação de funcionários com graduação tecnólogo. Fonte: Os autores.

Quanto a análise das disciplinas dos cursos tenólogos e a aplicação prática no ambiente de trabalho, verificou-se que 52,94\% dos entrevistados mencinam como "razoável" e $29,41 \%$ mencionam como "muito boa" a aderência das disciplinas a necessidade do mercado de trabalho. Percebe-se a visão enfática dos gestores de Joinville quanto a esse quesito. Essa percepção pode ser identificada pela representação do gráfico 3.

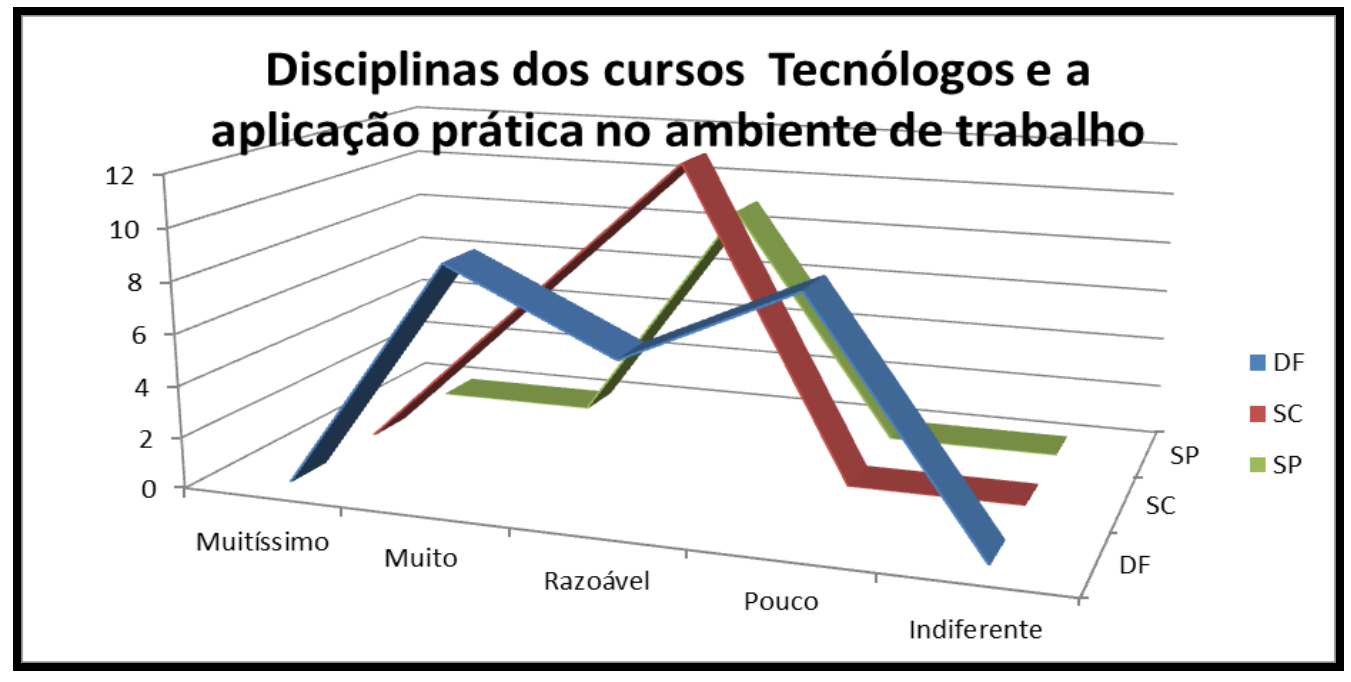

Gráfico 3 Disciplinas dos cursos tecnólogos e aplicação prática no ambiente de trabalho. Fonte: Os autores.

Em relação à aplicação das grades curriculares mais específicas dos cursos tecnólogos, 41,17\% dos gestores consideram "boa" e 35,29\% consideram "razoável” os conteúdos 
curriculares constantes das grades curriculares. Destaca-se a visão otimista dos gestores de Brasília em relação a adequação desses conteúdos, conforme apresentado no gráfico 4.

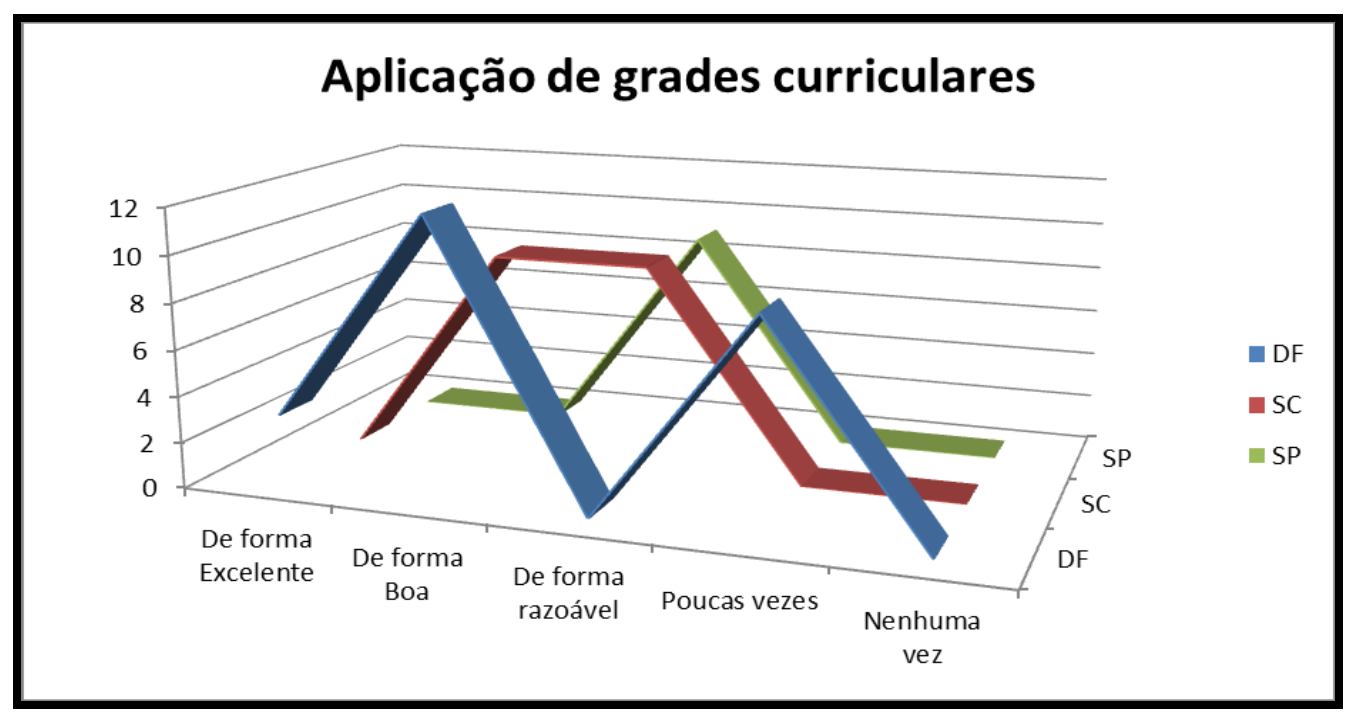

Gráfico 4 Aplicação de grades curriculares.

Fonte: Os autores.

$\mathrm{Na}$ análise da percepção do gestor quanto à disposição das empresas em articular a necessidade de conteúdo com as Instituições de Ensino Superior, percebe-se que "pouco" $(47,05 \%)$ e "razoável" (23,52\%) disposição em contribuir com essa articulação. Ainda verifica-se que a grande maioria dos gestores de São Paulo não oferecem disponibilidade para o diálogo com as Instituições de Ensino Superior. O gráfico 5 apresenta essa visão.

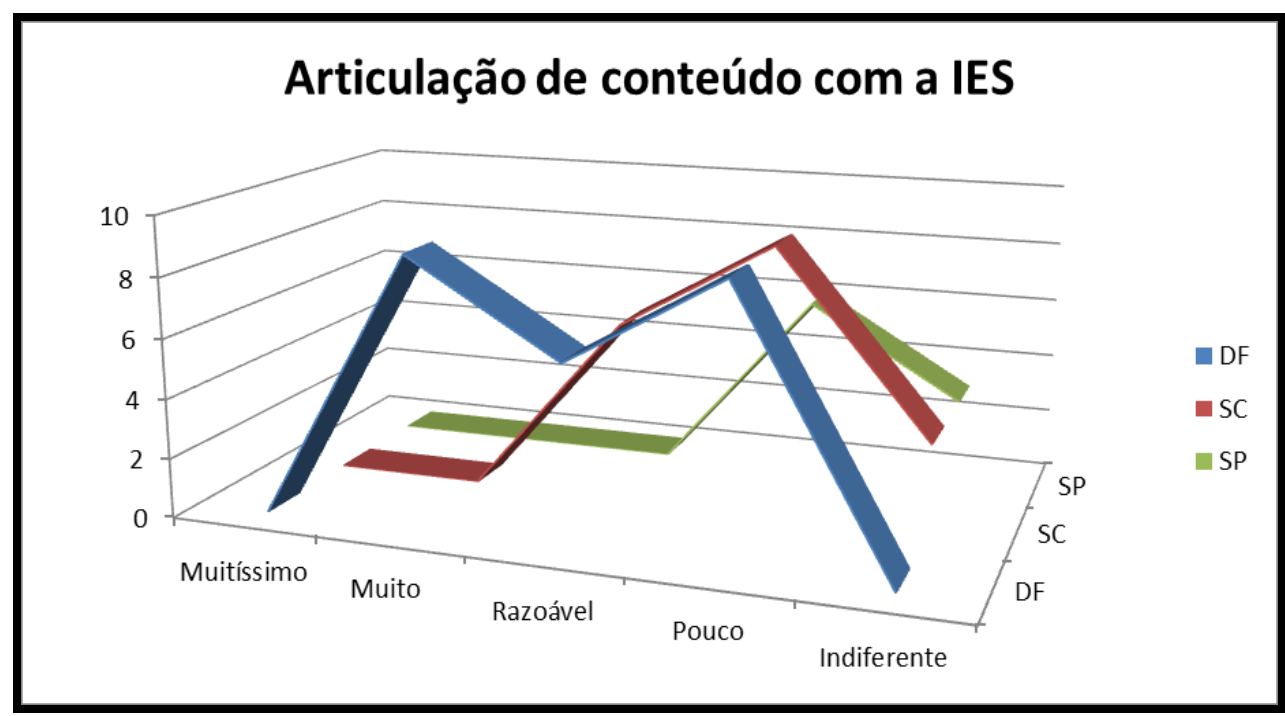

Gráfico 5 - Articulação de conteúdo com a IES. Fonte: Os autores. 
Com relação à análise da construção em conjunto da matriz curricular os cursos tecnólogos, verifica-se que "pouco" $(41,17 \%)$ dos gestores consideram importante essa parceira entre IES e empresas. Ainda $29,41 \%$ dos gestores consideram "indiferente" essa parceria. Destaca-se a visão contrária dos gestores de Joinville quanto a esse quesito. O gráfico 6 demonstra os dados dessa análise.

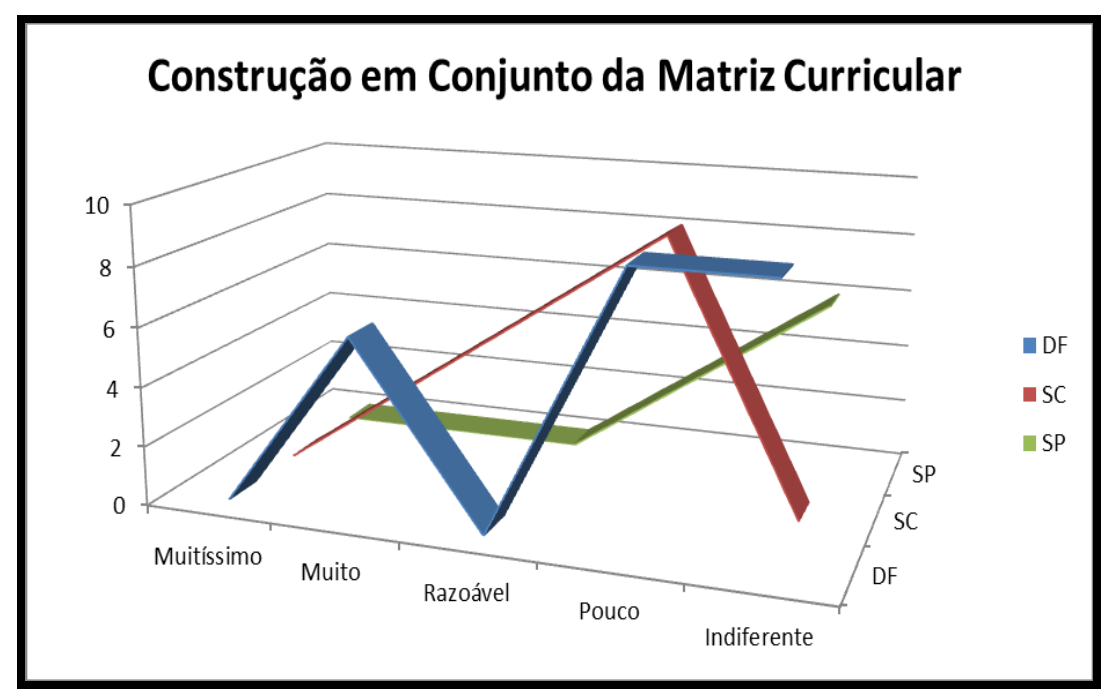

Gráfico 6 Construção em conjunto da matriz curricular, Fonte: Os autores.

\section{CONCLUSÃO}

Os cursos superiores de tecnologia não se articulam devidamente com o mundo do trabalho necessitando de uma atualização das políticas do ensino superior profissionalizante, faltando um sistema que perfaça o acompanhamento de ações que contemplem a gestão acadêmica destes cursos.

Os cursos superiores de tecnologia não tem demonstrado uma atualização das políticas de como podem interagir de forma eficiente com o mundo do trabalho, sendo objetos de demandas reprimidas, fincando com uma conotação finita de atuação.

De acordo com a análise dos gestores de empresas ainda falta muita integração entre as necessidades das atividades práticas das empresas e as Instituições de Ensino Superior, o que pode ser identificado com as respostas do instrumento de pesquisa apresentado nessa pesquisa. Talvez a aproximação das IES as empresas permitam a adequação das grades curriculares de despertem o interesse de gestores de empresas aos profissionais oriundos de cursos tecnólogos. 
$\mathrm{Na}$ análise da importância dos cursos superiores de tecnologia para o mercado de trabalho, os respondentes afirmam que os cursos são importantes, com um pequeno viés dos gestores de Brasília apresentando "pouca” (11.75\%) essa importância.

Quanto a análise das disciplinas dos cursos tecnólogos e a aplicação prática no ambiente de trabalho, verificou-se a visão enfática dos gestores de Joinville quanto a esse quesito que demonstraram este quesito de forma excelente. Uma das hipóteses para este argumento é a forte influencia industrial na cidade, conotando uma visão mais prática dos estudantes no que tange a aplicação dos conhecimentos científicos nas indústrias.

Em relação à aplicação das grades curriculares mais específicas dos cursos tecnólogos destaca-se a visão otimista dos gestores de Brasília em relação a adequação desses conteúdos, evidenciado pelo índice mais elevado das pesquisas.

$\mathrm{Na}$ análise da percepção do gestor quanto à disposição das empresas em articular a necessidade de conteúdo com as Instituições de Ensino Superior percebe-se que não há uma articulação entre as empresas e as IES o que fica muito mais evidente na região de São Paulo onde os gestores não oferecem disponibilidade para o diálogo.

Por fim, a construção em conjunto da matriz curricular os cursos tecnólogos, verifica-se que os poucos gestores consideram importante essa parceira entre IES e empresas e ainda alguns gestores, 29,41\%, consideram “indiferente" essa parceria. Destaca-se a visão contrária dos gestores de Joinville quanto a esse quesito.

Os gestores de empresas de Brasília ainda relataram que "os cursos tecnólogos são muitos rápidos e não atendem a expectativa do mercado". Ainda relatam que "os cursos tecnólogos precisam ser mais flexíveis em relação a grade curricular, devido a constantes mudanças da área de tecnologia”. Contudo, essas adequações podem ser atingidas com as alterações das grades curriculares dos cursos apontadas pelas necessidades do mercado.

A argumentação dos gestores de empresas de Joinville expressa a "necessidade de uma aproximação entre empresa e faculdade para que seja bem entendido a importância do conteúdo e disciplinas sejam úteis no mercado de trabalho, que está em constante mudança em função das necessidades dos clientes”. Dessa forma é possível entender a abertura das empresas a construir grades curriculares mais adequadas as necessidades do mercado de trabalho.

Na visão dos gestores de São Paulo “o maior problema é a pouca importância dada ao conteúdo curricular pelas Instituições de Ensino Superior não condizentes a expectativa do 
mercado de trabalho". Essa percepção retrata a falta de informação de determinados assuntos aplicados nas atividades da empresa.

As diretrizes acadêmicas devem estar organizadas a fim de permitir a evolução destes cursos perfazendo uma gestão acadêmica que possibilite uma melhor articulação entre o mundo do trabalho a academia.

Os cursos superiores de tecnologia não estão desenvolvendo as potencialidades do ensino superior profissionalizante na sua plenitude principalmente pela falta de interação das empresas no modelamento das matrizes curriculares, como desinteresse em algumas regiões do País, como na região de Brasília pelo real entendimento e necessidade dos cursos superiores de tecnologia.

Também as empresas pouco se articulam com o mundo do trabalho devendo esta premissa ser melhorada para que consigamos obter mais aproveitamento desta modalidade de ensino superior, de forma a oportunizar alunos, empresas e sociedade a se aperfeiçoar de forma mais rápida e direta nas ações do mundo do trabalho.

Desta forma conclui-se que a pesquisa alcançou seus objetivos onde respondeu as questões de pesquisa e percebesse há necessidade de pesquisas posteriores para que se diagnostique possibilidades reais de aproximação dos cursos de tecnologia a sua percepção favorável e interativa de gestores das empresas, associando assim a Universidade e o Mundo do Trabalho.

\section{REFERÊNCIAS}

BARROS, Davi Ferreira. (trabalhos apresentados). In: Seminário para administradores de um projeto educacional metodista, 2003.

BRISOLLA, S. N. Relação universidade-empresa: Como seria se fosse. In: Interação universidade/empresa. Brasília: IBICT, 1998.

COLAUTO, Romualdo Douglas; BEUREN, Ilse Maria. Coleta, análise e interpretação dos dados. In: BEUREN, Ilse Maria. Como elaborar trabalhos monográficos em contabilidade. São Paulo: Atlas, 2006.

FIORI, José Aparecido. Gestão do conhecimento empreendedor. Monografias premiadas no $2^{\circ}$ Concurso de Monografia sobre a Relação Universidade/Empresa. Curitiba: IPARDES, 2001.

GIL, Antonio Carlos. Métodos e técnicas de pesquisa social. 5 ed. São Paulo: Atlas, 1999. INEP - Instituto Nacional de Estudos e Pesquisas Educacionais $<<$ http://www.sinaes.inep.gov.br. Acesso em 20 fev. 2012. 
MARCONI, Marina de Andrade; LAKATOS, Eva Maria. Técnicas de pesquisa: planejamento e execução de pesquisas, amostragens e técnicas de pesquisa, elaboração, análise e interpretação. São Paulo: Atlas, 2002.

PLONSKI, Guilherme Ary. Cooperação empresa-universidade no Brasil: Um novo balanço prospectivo. In: Interação universidade-empresa. Brasília: IBICT, 1998.

PRADO, Fernando Leme do. Os novos cursos de graduação tecnológica. Curitiba/PR: OPET, 2006.

RICHARDSON, Roberto Jarry. Pesquisa Social: Métodos e Técnicas. 3. ed. São Paulo: Atlas, 1999.

RUIZ, João Álvaro. Metodologia científica: um guia para eficiência dos estudos. 4. ed. São Paulo: Atlas, 1996.

SCHNEIDER, Maria Clara Kaschny. Modelo de avaliação da gestão de instituição de cursos superiores de tecnologia. 2005. 207f. Tese (Doutorado em Engenharia de Produção) - Centro Tecnológico, Universidade Federal de Santa Catarina, Florianópolis, 2005.

VIEIRA, Fabiano M. e KUNZ, Ivanir. Ensinando e aprendendo a inovar: mecanismos de interação universidade/empresa visando à inovação tecnológica e ao desenvolvimento regional. Monografias premiadas no $2^{\circ}$ Concurso de Monografia sobre a Relação Universidade/Empresa. Curitiba: IPARDES, 2001. 